\title{
A PESQUISA AO LADO DOS PROTAGONISTAS DO ESTÁGIO SUPERVISIONADO EM BUSCA DE CAMINHOS PARA SEU ESPERADO DESEMPENHO
}

\author{
Menga LüDKE \\ Universidade Católica de Petrópolis (UCP), Petrópolis, Rio de Janeiro; \\ Pontifícia Universidade Católica do Rio de Janeiro (PUC- Rio), Rio de \\ Janeiro, Rio de Janeiro, Brasil \\ Sandra Cristina Motta Bortolotti \\ Natany Martins Bersan \\ Universidade Católica de Petrópolis (UCP), Petrópolis, Rio de Janeiro, \\ Brasil
}

\begin{abstract}
RESUMO: Apresentamos na primeira parte deste artigo a evolução pela qual o estágio vem passando, por leis e resoluções, nos diferentes contextos sócio históricos há 50 anos. Na segunda, abordamos como ele tem sido visto em dissertações e projetos desenvolvidos em nosso grupo de pesquisa. Na terceira parte, relacionamos constatações e questões levantadas por nossa pesquisa em torno dos três protagonistas do estágio, com uma proposta de análise paradigmática.
\end{abstract}

Palavras-chave: Formação de Professores. Estágio Supervisionado. Grupo de Pesquisa. Protagonistas do Estágio.

INTRODUÇÃO

O anúncio do volume 44, número 3 , da revista Inter-Ação, consagrado aos 50 anos da publicação da Resolução no 9, de 1969, relativo à regulamentação do Estágio Supervisionado como parte integrante do curso de formação inicial de professores para a educação básica, soou como um chamado imperioso para nosso grupo de pesquisa. Interessado nas questões da formação de professores desde a década de 1980, o Grupo de Estudos sobre a Profissão Docente, GEProf, tem se dedicado mais recentemente aos complexos problemas que cercam o estágio supervisionado, hoje reconhecido pelos estudiosos como um dos pontos mais frágeis do curso de licenciatura.

Em 2008, a partir de um chamado da Fundação Carlos Chagas Filho de Amparo à Pesquisa do Estado do Rio de Janeiro (FAPERJ), realizamos um pequeno estudo na perspectiva de aproximação entre a universidade e as escolas da educação básica no trabalho de pesquisa. Ainda que pequeno, o estudo representou um esforço muito bemsucedido (LUDKE, 2009a) e o estágio supervisionado consolidou-se como um dos temas 
centrais do trabalho de pesquisa do grupo e de sua coordenadora. Foram desenvolvidos projetos de pesquisa com apoio do CNPq (LUDKE, 2009b; 2012c; 2017a) e vários artigos (LUDKE, 2009c; 2013; LUDKE, RODRIGUES, RODRIGUES, 2017b; 2018a; 2018b) e capítulos de livros foram publicados (LUDKE, RODRIGUES, 2010; LUDKE, 2012a; 2012b; 2015), um Simpósio foi realizado em dezembro de 2015, além de dez dissertações de mestrado concluídas: CARDOZO, 2003; ALBUQUERQUE, 2007; RODRIGUES, 2009; PIRES, 2011; GUEDES, 2011; BAMBINO, 2012; ALMEIDA, 2013; FERREIRA, 2013; CARNEIRO, 2016; RIBEIRO, 2017.

O tema continua central para o trabalho do grupo, como o estágio supervisionado continua a representar um desafio no esforço para a formação de nossos professores, sendo, há muito, um dos problemas mais graves para o desenvolvimento do país. Várias iniciativas têm sido propostas em busca de caminhos que aproximem o trabalho da universidade e o das escolas nesse esforço, como o Programa Institucional de Bolsas de Iniciação à Docência (PIBID), com bolsas para estudantes e professores envolvidos e, mais recentemente, a Residência Pedagógica, procurando fortalecer o aspecto prático do curso de formação de professores.

São iniciativas recentes, com um número limitado de participantes, mas que já trazem experiências bem-sucedidas que podem servir como sugestões, talvez soluções, que possam ser orientadas para a ampla realidade das redes de ensino público da educação básica de todo o país. Lembremo-nos que, bem antes da Resolução focalizada neste número da revista, Anísio Teixeira, ainda nos anos de 1930, propunha a junção do trabalho formador da Escola Normal com o das escolas do ensino primário, em prédios anexos, nos quais os estudantes teriam assegurada sua prática de ensino formadora. Nasciam, assim, os futuros colégios de aplicação, dos quais há, até hoje, alguns remanescentes, tema de grande discussão e de importantes lições, que continuam a ocupar a atenção de seus estudiosos.

O estágio supervisionado continua, entretanto, como componente de frequência obrigatória no curso de licenciatura, segundo a lei que rege a formação de nossos futuros professores, em instituições que, muitas vezes, não contam com as condições básicas esperadas para o bom desenvolvimento desse curso. Estamos nos referindo ao grande número de estabelecimentos de ensino superior da rede privada, onde se forma grande parte, talvez mesmo a maioria de nossos futuros professores da educação básica. Habituamo-nos a mencionar a responsabilidade legalmente atribuída à universidade sobre a formação de professores, mas não damos a devida atenção à proporção de futuros docentes que não se beneficiam, em sua formação, dos recursos disponíveis nas universidades, de modo especial as do setor público e algumas poucas do setor privado.

É o caso, por exemplo, das iniciativas mencionadas, que procuram alternativas para atenuar os conhecidos problemas que cercam o trabalho do estágio supervisionado, centradas exclusivamente em instituições universitárias. Nossa pesquisa no GEProf tem se dirigido justamente aos problemas vividos por estudantes e professores dessas instituições do setor privado, a maior parte não universitárias, procurando levar adiante, como podem, o trabalho essencial que cabe ao estágio supervisionado para a formação de futuros professores. Temos tentado esclarecer, pelo esforço de busca, análise e discussão próprios do trabalho investigativo, os fatores e circunstâncias que cercam o 
estágio, travando seu desenvolvimento, impedindo-o de cumprir o importante papel que Ihe cabe no processo de formação de professores. Esperamos, com o esforço do esclarecimento, chegar a algumas ações alternativas que possam ser tentadas dentro das possibilidades atuais, embora reduzidas, e que representem algum avanço na direção esperada para o estágio.

Em nosso artigo, inicialmente, traremos um breve acompanhamento da evolução pela qual o estágio vem passando, por meio de leis e resoluções que procuraram orientá-lo, nos diferentes contextos sócio históricos dos 50 anos por ele vividos. Em uma segunda parte, procuramos apresentar um pouco de como ele tem sido visto e abordado em dissertações de nossos orientandos e nos projetos desenvolvidos em nosso grupo de pesquisa, o GEProf. Finalmente, na terceira seção, procuramos cotejar constatações e questões levantadas por nossa pesquisa em torno dos três protagonistas centrais do estágio, com uma análise paradigmática proposta por Paquay e Wagner, em 1996, que continua com grande atualidade em face dos problemas que parecem acompanhar o estágio há 50 anos.

\section{O ESTÁGIO NA SUCESSÃO DE LEIS E RESOLUÇÕES NOS ÚLTIMOS 50 ANOS}

Desde Anísio Teixeira até os dias atuais, a formação dos professores, bem como os aspectos acima citados, está em pauta, estimulando muitos pesquisadores a continuar discutindo e investigando sobre essa dimensão tão importante para a formação docente:

Contribuiria para a implantação desse ideário na escola a vital importância concedida à formação dos professores em suas proposições de políticas educacionais. Anísio via nos professores o "exército de paz" (1978, p. 104) cuja grande aventura democrática seria tentar "a renovação da Humanidade" (1978, p. 105). Acreditando que o preparo do magistério era uma necessidade de grande escala e urgência, entendia que se devia planejá-la como uma campanha para formar um exército para uma guerra já em andamento. (TEIXEIRA,1969, p. 240 apud EVANGELISTA, 1993, p. 103, grifo do autor).

Assim, em 1932, transformou a Escola Normal do Distrito Federal em Instituto de Educação, nele colocando uma Escola de Professores com jardim de infância e escola primária anexas. É possível perceber que a preocupação com a dimensão da prática na formação do professor já era bastante considerada:

O privilegiamento dado à prática de ensino evidenciava-se na existência, anexos à Escola de Educação, do jardim de infância e da escola primária, cujas funções se assemelhariam a laboratórios (também a escola secundária poderia, eventualmente, prestar-se a isso). Em tais locais existiriam classes experimentais, para aplicação e desenvolvimento de novos métodos, classes de demonstração, para observação do ensino modelo, e classes de prática de ensino, para aplicação dos conhecimentos adquiridos: regência propriamente dita. (EVANGELISTA, 1993, p. 105). 
Embora a preocupação com o aspecto da prática na formação de professores já há muito ocupasse as discussões no meio educacional, legalmente só toma forma com a Resolução CFE no 09 de 1969. O panorama histórico a seguir, que apresenta os encaminhamentos legais já feitos em torno da dimensão prática da formação dos professores, deixa claro que entre o proposto nas políticas educacionais e o vivido nas instituições formadoras há um distanciamento muito grande.

Há 50 anos era publicado pela primeira vez um documento dos órgãos oficiais que buscava inserir na formação dos professores a dimensão prática. A Resolução de 1969, em seu artigo art. 2०, instituía: "será obrigatória a Prática de Ensino das matérias que sejam objeto de habilitação profissional sob a forma de estágio supervisionado a desenvolverse em situação real, de preferência em escolas da comunidade" (BRASIL, 1969). Naquele mesmo ano, por determinação do Parecer 627/69, o estágio supervisionado passa a ter o tempo mínimo de $5 \%$ da carga horária do curso. 0 entendimento à época era que, ao realizar o estágio nas escolas, os futuros professores teriam a oportunidade de colocar em prática os conhecimentos adquiridos ao longo do seu curso, dentro das possibilidades e limitações de um contexto real.

Inicia-se na década de 1970 o modelo educacional tecnicista com o surgimento do ensino profissionalizante no segundo grau. A Lei de Diretrizes e Bases (LDB No 5.692/71) fixou diretrizes e bases para o ensino de $1^{\circ}$ e $2^{\circ}$ graus, propondo uma reestruturação para o Ensino Normal, que passa a ser uma habilitação específica. Após a lei, o Parecer CFE 349/72 foi publicado, tratando do "Exercício do magistério em $1^{\circ} \mathrm{grau}$, habilitação específica de $2^{\circ}$ grau", detalhando o que segue:

\begin{abstract}
A Didática fundamentará a Metodologia do Ensino, sob o tríplice aspecto de planejamento, de execução do ato docente-discente e de verificação da aprendizagem, conduzindo à Prática de Ensino e com ela identificando-se sob a forma de estágio supervisionado. Deverá a Metodologia responder às indagações que irão aparecer na Prática de Ensino, do mesmo modo que a Prática de Ensino tem que respeitar o lastro teórico adquirido da Metodologia (BRASIL, PARECER CFE n. 349/1972 apud ANDRADE, R. C. R.; RESENDE, M. R. 2010).
\end{abstract}

Nos anos de 1980, os movimentos sociais imputaram novas perspectivas para a escola e, nesta corrente, a formação dos professores, fazendo-se necessário, segundo Pimenta (2001), estabelecer outro formato para o Curso Normal, repensando os currículos para formar um professor comprometido com a transformação social. A discussão em torno da formação de professores se dava no bojo das disciplinas ditas pedagógicas e a prática de ensino referia-se ao estágio supervisionado, demonstrando uma visão fragmentada entre as formações.

Os movimentos dos anos 1980 deram início às reformas educacionais da década seguinte, culminando na promulgação da LDB 9.394/96, que buscou, em certa medida, atender aos anseios sociais no que tange à educação para todos. A referida Lei, ainda em vigor, mas alterada em alguns aspectos, definiu que a formação dos professores deve fundamentar-se na associação entre teorias e práticas, inclusive mediante a capacitação 
em serviço, garantindo também que a formação docente deva incluir prática de ensino e definir o estágio (Art. 82) como elemento obrigatório na composição curricular dos cursos de graduação com no mínimo 300 horas (Art. 65).

No começo dos anos 2000 inicia-se, então, o movimento de operacionalização dos encaminhamentos da LDB 9.394/96 e o Conselho Nacional de Educação (CNE) propõe as primeiras diretrizes curriculares nacionais para a formação de professores da educação básica, por meio da publicação do Parecer CNE/CP no $9 / 2001$, sendo suas propostas regulamentadas posteriormente pela Resolução de 18 de fevereiro de 2002.

Passa-se à compreensão de que a dimensão da prática profissional deva ocorrer ao longo do curso de formação como uma ação integrada, não apenas nos momentos de Estágio Supervisionado. De acordo com a resolução anteriormente citada, de 2002, em seu Art. $13 \S 3^{\circ}$, assim se define o estágio:

\begin{abstract}
O estágio curricular supervisionado, definido por lei, a ser realizado em escola de educação básica, e respeitado o regime de colaboração entre os sistemas de ensino, deve ser desenvolvido a partir do início da segunda metade do curso e ser avaliado conjuntamente pela escola formadora e a escola campo de estágio.
\end{abstract}

Considera-se, portanto, no referido Parecer, o Estágio Curricular Supervisionado como o tempo de aprendizagem em que se estabelece uma relação pedagógica entre alguém que já é um profissional reconhecido, em um ambiente institucional de trabalho, e um aluno estagiário. É por isso que esse momento se chama Estágio Curricular Supervisionado: é o período de efetivar, sob a supervisão de um profissional experiente, um processo de ensino-aprendizagem.

A carga horária destinada ao Estágio Supervisionado na formação de professores, antes prevista com 300 horas, passa a ser regulamentada pela Resolução de 19 de fevereiro de 2002 em 400 horas para a prática vivenciada ao longo da formação e 400 horas para o estágio curricular supervisionado, a partir da segunda metade do curso.

O estágio supervisionado, pelo menos no tocante à legislação, já é entendido como

\begin{abstract}
uma relação pedagógica entre alguém que já é um profissional reconhecido em um ambiente institucional de trabalho e um aluno estagiário. Tal contato oferece ao licenciando um conhecimento da realidade diretamente vivenciado em unidades escolares dos sistemas de ensino. Ele é, também, a oportunidade de acompanhar alguns momentos da vida escolar, tais como: a elaboração do projeto pedagógico, da matrícula, da organização de turmas e do tempo e espaços escolares, relacionando-se, assim, a teoria com a prática (LONGUINI; NARDI, 2004 apud FERRAZ \& MEGLHIORATTI, 2013).
\end{abstract}

Sobre a prática como componente curricular, podemos entendê-la como a articulação entre os conteúdos trabalhados nas disciplinas específicas e os conhecimentos pedagógicos. É o que Almeida (2007) denominou "transposição didática", ressaltando que o que se pretende ensinar deve submeter-se ao como ensinar, uma relação entre teoria e prática, na contínua reflexão entre o saber e o fazer. Desta forma, com a orientação de que aconteça ao longo do curso de formação de professores, 
subentende-se que a prática possa influenciar a atuação do aluno estagiário no momento de sua inserção no espaço escolar. O Parecer CNE/CP no 9/2001 define como "uma dimensão de conhecimento que está presente nos diversos momentos, durante 0 processo de formação em que se reflete sobre a atividade profissional" (BRASIL, 2001).

Todavia, como todo conhecimento em construção encontra-se sujeito a vários olhares e interpretações, as autoras Pimenta e Lima (2004) entendem que a organização dada pela Resolução de 2002, que separa as horas de prática das de estágio supervisionado, perpetua a histórica separação entre teoria e prática reforçando o entendimento de que o estágio seria momento de treinamento e aprendizagem de práticas modelares.

Ainda que não esteja relacionada especificamente à formação de professores, mas sim a toda atividade profissional, fazemos aqui uma breve menção à Lei $\mathrm{n}{ }^{\circ} .11 .788$ de 2008, ainda em vigor, que dispõe sobre as atividades de estágio de estudantes, regulamentando o que segue:

Art. $1^{\circ}$ Estágio é ato educativo escolar supervisionado, desenvolvido no ambiente de trabalho, que visa à preparação para o trabalho produtivo de educandos que estejam frequentando o ensino regular em instituições de educação superior, de educação profissional, de ensino médio, da educação especial e dos anos finais do ensino fundamental, na modalidade profissional da educação de jovens e adultos. (BRASIL, 2008).

No ano de 2009, a Resolução CNE no 1, de 11 de fevereiro de 2009, estabeleceu Diretrizes Operacionais para a implantação do Programa Emergencial de Segunda Licenciatura para Professores em exercício na Educação Básica Pública. Também apresentou organização específica para o estágio supervisionado, definindo a carga horária do estágio em 200 (duzentas) horas, com as atividades realizadas na própria escola, orientadas por um projeto de melhoria e atualização do ensino, realizado sob supervisão concomitante da instituição formadora e da escola (BRASIL, 2009).

Finalizando esse panorama do histórico legal que versa sobre a temática estágio supervisionado na formação de professores, apresentamos a Resolução CNE/CP no 2 , de 2015, que define as atuais Diretrizes Curriculares Nacionais para a formação inicial em nível superior e para a formação continuada. A Resolução mantém os mesmos parâmetros da Resolução CNE/CP no 2/2002 no tocante à carga horária, tanto para estágio supervisionado quanto para a prática, definindo o estágio como componente obrigatório da organização curricular das licenciaturas.

\section{O ESTÁGIO VISTO POR PESQUISADORES DO GEProf}

Em meio à grande discussão a seu respeito, na época fomos levados a nos interessar pelo tema do estágio por algumas orientandas, professoras da educação básica, preocupadas com seus problemas. A primeira, Solange Cardozo (2003), vê o estagiário confinado ao papel de mero observador, ao fundo da sala, "decorativo como uma samambaia", em sua expressão; a segunda, Sabrina Albuquerque (2007), constata a 
distância entre o professor que recebe o estagiário em sua sala de aula e não se percebe como coformador desse estudante, e a universidade, que parece não o perceber também. Outras foram chegando, ajudando a desvelar fragilidades desse importante componente do processo de formação de professores e também trazendo sugestões inspiradas em como se desenvolve o estágio na formação de futuros profissionais de outras áreas.

Ao final de 2007, a FAPERJ, lançou uma chamada para financiamento de pesquisas em educação que procurassem aproximar pesquisadores da universidade e professores das escolas da rede pública da educação básica. O financiamento se destinava exclusivamente ao pessoal da escola, com bolsas para dois professores que participariam diretamente da pesquisa e um pequeno auxílio financeiro à diretoria da escola para responder a alguma necessidade urgente do estabelecimento. Estimuladas pelas constatações das dissertações de Cardoso (2003) e Albuquerque (2007), mas, sobretudo, muito impressionadas com a gravidade dos problemas que cercavam (e ainda cercam) o estágio, resolvemos investigar de perto como ele transcorria de fato e entramos no desafio proposto.

O êxito do estudo foi muito além do esperado e deixou patente a importância da aproximação entre universidade e escola pela pesquisa, dentro dos limites oferecidos por uma análise de curta duração. Mesmo com poucos recursos, as lições nos estimularam a aprofundar os estudos sobre o estágio e a continuar a busca pelo significado e pela possibilidade da pesquisa ligada ao professor e possivelmente realizada por ele, tanto pela importância para o seu desenvolvimento como profissional como pela própria pesquisa em educação.

Continuando com os trabalhos de mestrandos, membros do GEProf, Priscila Rodrigues (2009) ampliou a lente da pesquisa realizada (2009a) para abranger toda a escola, como participante na coformação do estagiário, futuro professor. Já Francisca Pires (2011) focalizou essa lente sobre o orientador do estágio, encarregado na universidade de acompanhar de perto o estudante nesse período crucial, mas muito pouco amparado nesse difícil trabalho pela instituição formadora.

Evelyne Guedes (2011) trouxe, da formação do futuro odontólogo, a configuração do estágio como um acompanhamento individual, de cada estagiário, pelo preceptor responsável por cada uma das áreas de atuação básica do futuro dentista. Erika Bicalho de Almeida (2013), por sua vez, relatou a realização do estágio do futuro enfermeiro, sob a supervisão de um preceptor responsável, mas desenvolvido em conjunto com vários profissionais da enfermagem, que compõem sua equipe e dividem com ele a iniciação do estagiário nas várias habilidades previstas para o futuro profissional.

Vivian Bambino (2012) penetrou em área de difícil trânsito, muito pouco visitada por estudos sobre a formação de professores, na qual se confrontam as duas instituições responsáveis por essa formação, a universidade e a Secretaria Municipal de Educação. Seu estudo confirmou o que já era percebido por estudiosos do tema: a falta de diálogo efetivo entre essas instituições, com repercussões marcantes sobre aquela formação.

Ana Paula Lourenço Ferreira (2013), conhecedora da formação tradicional da futura professora para o primeiro segmento do ensino fundamental, antigo ensino primário, pela Escola Normal, investigou uma questão muito discutida em nossas reuniões do grupo de pesquisa: as diferenças entre as estudantes que cursaram o antigo Curso Normal ou o atual Curso de Magistério e as que não os cursaram. Suas constatações 
mostram que há várias diferenças claras, entre as quais a familiaridade com o trato com as crianças, coisa que as "não normalistas" se queixam de não ter. Outra diferença evidente é o exercício da prática docente, que as oriundas do curso normal já trazem, em geral, e as outras não.

Vanderleia Carneiro (2016), professora de química e membro do nosso grupo de pesquisa, interessou-se por analisar o desempenho de alunos do estágio supervisionado e de bolsistas do PIBID, já que trabalha em duas instituições que recebem os dois grupos de alunos. Suas constatações, além de confirmar suposições que já vêm circulando no meio acadêmico, levantam outro tipo de suposição, quanto ao significado da participação dos professores de várias disciplinas em relação à preparação pedagógica específica e, por consequência, o estímulo e interesse sobre a formação de professores. Também analisou efeitos da situação desigual entre professores supervisores de estágio e professores coordenadores de pesquisas em suas áreas, bolsistas e não bolsistas.

Completando dez dissertações de mestrado, desenvolvidas dentro do GEProf e ligadas ao estágio, temos um neurocirurgião, Antônio Ribeiro (2017), trazendo uma perspectiva de grande e antigo interesse para nós: o confronto entre a preparação para a prática docente dos futuros professores e para a prática médica dos futuros profissionais da medicina. Sua pesquisa revela com detalhes como acontece, durante os dois anos de internato, a articulação entre a formação teórica e a prática. Ao lado desta invejável constatação, ele procurou ver de perto como se desenvolve a relação entre o estudante em formação e a prática da pesquisa, bem como o entendimento da importância dessa relação para o futuro profissional da medicina, durante toda a sua carreira, tema de grande interesse para o estudo da formação de professores, com os quais, em geral, não ocorre essa relação.

Decidimos privilegiar no estudo que se seguiu a visão dos principais protagonistas do trabalho com o estágio, com base em sua atuação específica. Para tanto, procuramos nos aproximar dos atores cujos papéis são centrais para o desenrolar desse trabalho. O primeiro é o professor da universidade, ou da Instituição de Ensino Superior (IES), encarregado da orientação dos estudantes que se matriculam nos cursos de licenciatura, com o objetivo de se tornarem professores. O segundo protagonista é o professor das escolas, que recebe os estagiários em sua sala de aula e tem que encontrar meios de apresentar a eles um trabalho essencial para o desenvolvimento dos cidadãos em formação sob sua guarda. Nossa pesquisa procura ouvir esses profissionais e divulgar seus relatos sobre como conseguem realizar esse trabalho e que sugestões podem oferecer a partir de sua atuação específica em relação ao estágio, mesmo dentro de condições de trabalho limitadas.

Chegamos ao terceiro protagonista, figura central do tema em foco, o estagiário, em geral visto na cena do estágio como subordinado às normas e regras que regem a sua formação pela instituição de ensino superior. Dele é esperado obedecer e seguir à risca essas normas e regras, preenchendo formulários, redigindo relatórios formais, cumprindo planos e prazos pré-definidos e preestabelecidos, sem nada que corresponda, de fato, à sua posição como sujeito central do estágio.

Ao final do ano de 2015, em dezembro, realizamos um encontro para reunir e apresentar ao público interessado as constatações de nosso estudo até então, bem como 
propostas para sua continuidade. $O$ encontro foi muito bem-sucedido, oferecendo, pela própria voz de nossos protagonistas, um grande número de reflexões e sugestões, algumas delas já constatadas, discutidas e analisadas nas reuniões semanais do nosso grupo de pesquisas, o GEProf.

\section{QUESTÕES LEVANTADAS NO ESTUDO EM FACE DE UMA ANÁLISE PARADIGMÁTICA}

Os estágios de campo constituem sem contestação um momento importante na formação do ofício de professor. Mas a filosofia desses estágios difere fortemente segundo o paradigma adotado. (PAQUAY e WAGNER, 1996, p. 164).

Os protagonistas do trabalho com o estágio supervisionado nos ofereceram importante contribuição para seu estudo, durante sua participação no Simpósio que os reuniu em dezembro de 2015. Vamos trazer uma súmula das principais questões e sugestões levantadas por eles, na tentativa de melhor entendê-las, à luz do esquema paradigmático proposto por Paquay e Wagner (1996). Muitas delas vêm sendo apontadas em nossas pesquisas anteriores e mesmo pela literatura relativa, mas ganharam um vigor especial como uma indicação clara de sua atualidade na voz de nossos protagonistas, que as estão vivenciando hoje em suas escolas e instituições de ensino superior, como orientadores, supervisores e estagiários, figuras centrais do estágio supervisionado.

a- Ligadas ao professor orientador

Falta de clareza sobre o lugar do estágio no curso de licenciatura e de preparação específica do professor orientador, responsável pela disciplina relativa ao estágio supervisionado. Falta de condições básicas para o trabalho de acompanhamento dos estagiários junto às escolas, o que acaba dependendo de esforços pessoais "extras" para conseguir a interação indispensável, que deveria ser institucionalizada e não na base da "camaradagem".

b- Ligadas ao professor supervisor nas escolas

$O$ receio, quase inconsciente, pairando como um fantasma sobre a figura do estagiário como um possível (e temível) avaliador do trabalho do professor que o recebe em sua sala de aula. Falta de clareza e de preparação específica sobre o trabalho coformador esperado do professor supervisor, de modo especial no que diz respeito à avaliação do estagiário em seu desenvolvimento no estágio. Entra aqui a questão do que é esperado que ele de fato desempenhe como a docência compartilhada, ainda muito pouco compreendida e efetivada, como bem assinala Calderano (2017). Foi bastante ressaltado o papel fundamental da direção, bem como dos outros membros do estabelecimento escolar no acolhimento e acompanhamento do estagiário.

C - Ligadas ao estagiário

A idealização do estágio por parte dos estudantes, com a consequente decepção, em geral, com a realidade encontrada, sem uma efetiva preparação dos professores que os recebem, bem como de toda a equipe escolar. Importância de uma boa introdução do estagiário, com uma identidade própria, não professor 
ainda, mas já não mais apenas aluno. Dificuldade para encontrar escolas disponíveis para o estágio, com horários compatíveis com as atividades desenvolvidas pelos estudantes, muitos deles trabalhando para assegurar o pagamento do curso. O estágio reduzido a atividades auxiliares ao trabalho docente, realizado exclusivamente pelo professor, que deverão integrar o relatório final, ao lado da descrição detalhada da escola, de sua história e seu plano de trabalho a partir de documentos fornecidos pela direção. Isso tudo em um formulário padronizado pela instituição de ensino superior, cujo preenchimento é considerado cansativo e apenas burocrático pelos estagiários. Sem se esquecer de relatar o único trabalho prático com toda a turma de alunos que o estudante deve apresentar. A falta de autonomia foi bastante ressaltada pelos estagiários durante o simpósio, deixando patente seu constrangimento por não poderem sugerir soluções que consideram interessantes para alguns dos problemas encontrados entre os alunos, dentro, por certo, das normas vigentes na escola.

Trouxemos um conjunto compacto de questões, algumas há muito perturbando o caminho já longo do estágio (desde 1969), reavivadas pela voz dos que estamos focalizando em nossa pesquisa como seus protagonistas principais. Há várias outras, de igual importância, que continuam a requerer nossa atenção e serão apenas mencionadas, devido aos limites do texto. Entre elas, a complexa questão do estágio remunerado, não válido para cumprir as exigências curriculares, porém de grande valia, segundo os estudantes que passam por ele, por assegurar a efetiva prática docente, tão reclamada do estágio supervisionado, além da óbvia contribuição para a manutenção do estudante; $\mathrm{e}$ também a questão da pesquisa ligada à formação do futuro professor e à prática do já profissional docente. Nessas discussões registram-se, muitas vezes, impasses entre os debatedores situados em pontos de partida até opostos. Paquay e Wagner (1996) propuseram uma série de paradigmas que poderão ajudar ao menos a esclarecer alguns impasses, ao indicarem para onde se volta cada paradigma e por onde passam em seu caminho. Vamos trazê-los, em uma tradução nossa, esperando que possam contribuir para esclarecer nossos debates sobre os complexos problemas do estágio:

10 Paradigma: Um "professor instruído"? - Os estágios vêm sempre em lugar secundário em importância e em duração em relação à formação teórica, depois de uma formação disciplinar aprofundada e uma formação pedagógica e metodológica teórica. São ocasiões para aplicar as teorias aprendidas anteriormente. Objetivo: aplicar os saberes e teorias aprendidos.

2० Paradigma: Um técnico - Os estágios são um complemento para uma formação técnica e teórica. Uma formação técnica progressiva encontra sua finalização nos estágios ao final da formação. Objetivo: automatizar técnicas de saber-fazer.

3० Paradigma: Um "praticien" artesão - De difícil tradução, a palavra praticien, em francês, não corresponde simplesmente a "prático" ou a "praticante", mas a alguém engajado na prática de alguma profissão. Segundo os autores, dentro desse paradigma, os estágios vêm antes em importância e em duração em relação à formação teórica. Eles intervêm desde o início de uma formação em alternância e em casos extremos concentram toda a formação no campo. Objetivo: adquirir "a mão certa do ofício". 
4० Paradigma: Um "praticien" reflexivo - Os estágios são importantes como momentos de experimentação, como base de uma reflexão. A formação se estrutura em alternância, e os estágios diversos e sucessivos são preparados e, sobretudo, explorados. Objetivo: desenvolver um saber de experiência teorizada.

50 Paradigma: Um ator social - Os estágios são importantes como uma ocasião de engajamento em um ofício coletivo. No início da formação, são estágios de análise de situações complexas. Ao final da formação, são estágios de engajamento em projetos inovadores. Objetivo: Engajar-se em projetos coletivos inovadores.

6 Paradigma: (Uma pessoa) um profissional - Os estágios são importantes como uma ocasião de afirmação de si como profissional e de desenvolvimento pessoal. Em diversos momentos da formação os estágios são ocasiões de se construir uma identidade profissional. Objetivo: desenvolver seu "eu" profissional, tomar consciência de seu estilo pessoal, estar em dinâmico desenvolvimento pessoal.

Os autores acautelam os leitores sobre os limites de uma proposta desse tipo, procurando reunir traços fundamentais que distinguem diferentes perspectivas ou visões, que eles propõem como paradigmáticas. Para fins de discussão, parece-nos bastante útil trabalhar com essa tentativa de classificação, que pode ajudar a ver o que se coloca como alvo de cada "paradigma", ainda que de forma apenas esquemática, e quais suas implicações, se forem postos em prática. Neste ponto, os autores são ainda mais insistentes, pedindo atenção para as práticas adotadas, que podem mesmo ser incoerentes em relação ao "paradigma" proposto. Eles também ressaltam que os envolvidos nos debates sobre o papel e o lugar do estágio na formação de professores, em geral, entram em acordo com os colegas de diferentes posições, ou "paradigmas", para formular propostas mais factíveis. Em uma interessante discussão entre oponentes em um debate fictício, presente no texto, há uma série de argumentações que ilustra bem essa situação. Vamos sumariar uma delas:

\begin{abstract}
Estou de acordo para os estágios logo no começo da formação. Mas não em quaisquer condições. Se você não os preparar desde o começo para compreender o que eles fazem, a fazer escolhas racionais, você vai fabricar autômatos incapazes de reflexão, de autonomia e de adaptação. Aliás, o ideal seria que eles pudessem fazer um estágio-pesquisa, um estágio onde eles pudessem experimentar novidades pedagógicas (PAQUAY, L.; WAGNER, M-C., 1996, p. 164).
\end{abstract}

O capítulo de Paquay e Wagner é rico de reflexões e sugestões muito interessantes e oportunas para as nossas discussões sobre o estágio, como é todo o livro, organizado por autores muito próximos de nossos estudos, como Altet e Perrenoud, além de Paquay e Charlier. Quisemos trazer a proposta dos paradigmas, em especial, porque se aproxima muito, a nosso ver, da situação que vivemos hoje ao enfrentarmos os problemas do estágio, por certo com muito mais desafios dos que enfrentam os autores em seu país, a Bélgica. Mas o esquema proposto abrange de forma clara a diversidade de perspectivas pelas quais o estágio é visto entre nós, ajudando-nos a levar a discussão para colegas orientadores de estágios e para os estudantes que estão passando por eles, de modo a abrir possíveis horizontes em novas perspectivas, no confronto entre os vários paradigmas propostos, ainda que de modo esquemático. 
Em meio a novas perspectivas e sempre dentro das condições atuais em que se desenvolvem nossos estágios, em sua maioria em instituições privadas com recursos limitados, queremos finalizar nosso texto acenando para uma notícia que poderá representar um real avanço em direção a uma reivindicação há muito esperada. A situação de trabalho do professor supervisor, que recebe e acompanha os estagiários em sua escola e em sua sala de aula, sem receber compensação alguma em termos de salário ou de redução de carga horária, poderá ser beneficiada por uma medida proposta, já acolhida pela Secretaria de Educação do Estado do Paraná, para atribuir pontos aos professores das escolas da rede estadual que receberem estudantes estagiários. Esses pontos, de acordo com alguns critérios estabelecidos, entrarão na contagem de pontos para os concursos e a progressão na carreira desses professores. A medida já foi aprovada e está em trâmites de efetivação. Consideramos que ficará marcada como um importante ponto inicial em direção ao reconhecimento oficial de um trabalho fundamental no processo de formação de futuros professores, em conjunto com seus colegas, professores orientadores do curso de licenciatura. Podemos considerá-lo como um tento, ainda que bastante tardio, marcando a celebração dos 50 anos da Resolução, no 9 de 1969.

Artigo recebido em: 21/12/2018 Aprovado para publicação em: 27/05/2019

\section{RESEARCH DEVELOPED WITH PROTAGONISTS OF SUPERVISED INTERNSHIP TOWARDS A BETTER PERFORMANCE}

ABSTRACT: We initially present the evolution of the internship through different social historical contexts during the last 50 years. Secondly, we focus on the way it has been discussed in dissertations elaborated in our research group. Thirdly, we relate conclusions and questions proposed by our research around the three internship protagonists, proposing a paradigmatic analysis.

KEYWORDS: Teacher Education; Supervised Internship; Research Group; Protagonists of the Internship.

\section{LA INVESTIGACIÓN JUNTO A LOS PROTAGONISTAS DE LAS PRÁCTICAS SUPERVISADAS EN BUSCA DE CAMINOS PARA SU DESEMPEÑO ESPERADO}

RESUMEN: Presentamos en la primera parte la evolución por la cual la plasantía viene pasando por leyes y resoluciones en los diferentes contextos socio-históricos desde hace 50 años. En la segunda, abordamos cómo la pasantía ha sido estudiada en disertaciones y proyectos desarrollados en nuestro grupo. En la tercera parte, relacionamos constataciones y cuestiones planteadas por nuestra investigación en torno a los tres protagonistas de la pasantía, con una propuesta de análisis paradigmático. 
LÜDKE, M.; BORTOLOTTI, S. C. M.; BERSAN, N. M.

PALABRAS CLAVE: Formación de Profesores; Pasantía Supervisada; Grupo de Investigación; Protagonistas de la Pasantía.

\section{REFERÊNCIAS}

ALBUQUERQUE, S. B. G. Estágio Supervisionado e parceria na formação de professores. 2007. Dissertação (Mestrado em Educação) - Departamento de Educação, Pontifícia Universidade Católica do Rio de Janeiro, Rio de Janeiro, 2007.

ALMEIDA, G. P. de. Transposição didática: por onde começar? São Paulo: Cortez, 2007.

ALMEIDA, E. B. de O estágio supervisionado: entre futuros enfermeiros e futuros professores. 2013. Dissertação (Mestrado em Educação) - Departamento de Educação, Universidade Católica de Petrópolis, Petrópolis, 2013.

ANDRADE, R. C. R.; RESENDE, M. R. Aspectos legais do estágio na formação de professores: uma retrospectiva histórica. Educação em Perspectiva, Viçosa, v. 1, n. 2, p. 230-252, jul./dez. 2010.

BRASIL. Resolução CNE/CP no 2, de $1^{\circ}$ de julho de 2015. Disponível em: http://portal.mec.gov.br/. Acesso em 10 dez. 2018.

BRASIL. Resolução CNE no 1, de 11 de fevereiro de 2009. Disponível em: http://portal.mec.gov.br/. Acesso em 10 dez. 2018.

BRASIL. Lei $n^{\circ} .11 .788$ de 2008. Disponível em: http://www2.planalto.gov.br/.Acesso em 10 de dez. 2018.

BRASIL. Resolução CNE/CP no 1 de 18 de fevereiro de 2002. Disponível em: http://portal.mec.gov.br/. Acesso em 10 dez. 2018.

BRASIL. Resolução CNE/CP no 2 de 19 de fevereiro de 2002. Disponível em: http://portal.mec.gov.br/. Acesso em 10 dez. 2018.

BAMBINO, V. P. O Estágio supervisionado e as instituições responsáveis em diálogo. 2012. Dissertação (Mestrado em Educação) - Departamento de Educação, Universidade Católica de Petrópolis, Petrópolis, 2012.

CALDERANO, M. A. O Estágio Curricular e a Docência Compartilhada: na Perspectiva do Realismo Crítico. Curitiba: Appris, 2017

CARDOZO, S. A. Universidade e Escola: Uma via de mão dupla? 2003. Dissertação (Mestrado em Educação) - Departamento de Educação, Pontifícia Universidade Católica do Rio de Janeiro, Rio de Janeiro, RJ, 2003. 
CARNEIRO, V. A. F. Formação do futuro professor: Estágio e PIBID. 2016. Dissertação (Mestrado em Educação) - Departamento de Educação, Universidade Católica de Petrópolis. Petrópolis, 2016.

EVANGELISTA, O. Anísio Teixeira e a educação: um roteiro possível de leitura (19301950).Revista Perspectiva, Florianópolis, v. 11, n. 20, 1993.

FERRAZ, D.; MEGLHIORATTI, F. A. Panorama atual do desenvolvimento da Prática de Ensino e dos Estágios Supervisionados do curso de Licenciatura em Ciências Biológicas da Universidade Estadual do Oeste do Paraná. Educação Santa Maria; Santa Maria, v. 38; n. 2; p. 305-318; maio/ago. 2013.

FERREIRA, A. P. L. Estudantes que cursaram ou não o Normal frente ao estágio no curso de Pedagogia. 2013. Dissertação (Mestrado em Educação) - Departamento de Educação, Universidade Católica de Petrópolis, Petrópolis, 2013.

GUEDES, E. A. O estágio supervisionado na formação de futuros profissionais nas áreas da educação e da saúde: o caso da odontologia. 2011. Dissertação (Mestrado em Educação) - Departamento de Educação, Universidade Católica de Petrópolis, Petrópolis, 2011.

LUDKE, M.; SCOTT, D. O lugar do estágio na formação de professores em duas perspectivas: Brasil e Inglaterra. Educação \& Sociedade (Impresso), Campinas, v. 39, p. 109-125, 2018a.

LUDKE, M. Uma análise da formação de professores da educação básica em duas realidades. Instrumento: Revista em Estudo e Pesquisa em Educação, v. 20, p. 13-27, 2018b.

LUDKE, M.Problemas do estágio supervisionado no magistério e sugestões de seus protagonistas. Projeto de Pesquisa. CNPq: Rio de Janeiro, 2017a.

LUDKE, M. Estágio supervisionado: substantivo fictício? In: GATTI, B. A. et al. (orgs.). Por uma revolução no campo da formação de professores. 1. ed. São Paulo: Unesp, 2015, p. 171-185.

LUDKE, M. O lugar do estágio na formação de professores. Educação em Perspectiva, Viçosa, v. 4, n. 1, p. 111-133, jan./jun. 2013.

LUDKE, M. A formação para o trabalho docente e o estágio supervisionado. In:SANTOS, L. L. de C. P. e FAVACHO, A. M. P. Políticas e práticas curriculares: desafios contemporâneos. Curitiba: CRV, 2012a, p. 51-63. 
LÜDKE, M.; BORTOLOTTI, S. C. M.; BERSAN, N. M.

LUDKE, M. O estágio e seu papel na socialização profissional de professores. In: REBOLO, F. et al. (orgs.). Docência em questão: discutindo trabalho e formação. Campinas: Mercado de Letras, 2012b, p. 161-180.

LUDKE, M.O estágio analisado a partir da atuação dos seus componentes. Projeto de Pesquisa. CNPq: Rio de Janeiro, 2012c.

LUDKE, M.O estágio na formação docente, entre a universidade e a escola de educação básica, como campo de cruzamento de saberes. Relatório de Pesquisa. Faperj: Rio de Janeiro, 2009a.

LUDKE, M. O estágio na formação docente: ponto de convergência ou de estrangulamento? Projeto de Pesquisa. CNPq: Rio de Janeiro, 2009b.

LUDKE, M. Universidade, escola de educação básica e o problema do estágio na formação de professores. Formação Docente. Revista Brasileira de Pesquisa sobre Formação de Professores, v. 1, p. 95-108, 2009c. Disponível em https://revformacaodocente.com.br/index.php/rbpfp/article/view/7 . Acesso em: $10 \mathrm{dez}$. 2018

LUDKE, M.; ALMEIDA, E.B; SILVA, A. L. B. de. Contribuiciones de la Etapa Supervisada para la formación de la identidad profesional de las enfermeras. Cultura de los cuidados, $\mathrm{n}$. 48, p. 131-139, 2017b. Disponível em http://www.academia.edu/34577196/Cultura_de_los_Cuidados.Revista_de_Enfermer\% C3\%ADa_y_Humanidades._XXI_48. Acesso em: $10 \mathrm{dez} .2018$

LUDKE, M.; RODRIGUES, P. A. M. O estágio como porta de entrada para o trabalho docente. In: CORDEIRO, A. F. M. et al. (orgs.). Trabalho Docente: formação, práticas e pesquisa. Joinville: Editora Univille, 2010, p. 29-46.

PAQUAY, L.; WAGNER, M-C. Les six paradigmes en action. In: PAQUAY, L. et al. (orgs.) Former des enseignants professionnels: Quelles stratégies: Quelles compétences? Département de Boeck Université Paris, Bruxelles, 1996.

PIMENTA, S. G. O Estágio na formação de Professores: unidade teoria e prática? 4. ed. São Paulo: Cortez, 2001.

PIMENTA, S. G. O Estágio na formação de Professores: unidade teoria e prática? 4. ed. São Paulo: Cortez, 2001. PIMENTA, S. G.; LIMA, M. S. Estágio e docência. São Paulo: Cortez, 2004.

PIRES, F.C. O. O papel do professor orientador na efetiva-ação do estágio: múltiplas visões. 2011. Dissertação (Mestrado em Educação) - Departamento de Educação, Universidade Católica de Petrópolis, Petrópolis, 2011. 
RIBEIRO, A. H. N. A prática e o estágio supervisionado: entre futuros médicos e futuros professores. 2017. Dissertação (Mestrado em Educação) - Departamento de Educação, Universidade Católica de Petrópolis, Petrópolis, 2017.

RODRIGUES, P. A. M. Anatomia e fisiologia de um estágio. 2009. Dissertação (Mestrado em Educação) - Departamento de Educação, Pontifícia Universidade Católica do Rio de Janeiro, Rio de Janeiro, 2009.

SIMPÓSIO SOBRE PRÁTICA DOCENTE E ESTÁGIO SUPERVISIONADO (I) -1, 2015, Simpósio sobre a prática docente e estágio supervisionado, Petrópolis, RJ.

Menga LüdKE: Doutora em Sociologia. Professora do Departamento de Educação do Centro de Ciências Humanas da Pontifícia Universidade Católica do Rio de Janeiro e da Universidade Católica de Petrópolis.

Orcid: https://orcid.org/0000-0002-3202-5101

E-mail:mensa@puc-rio.br

Sandra Cristina Motta Bortolotti: Formação em Pedagogia com especialização em Psicopedagogia e Gestão Escolar; Mestrado em Educação e doutoranda em Educação pela Universidade Católica de Petrópolis. Professora de Educação Básica na Rede Municipal de Ensino de Petrópolis; Assessora Pedagógica da Pró-Reitoria de Graduação da Universidade Católica de Petrópolis e professora na graduação dos cursos de Pedagogia e demais licenciaturas.

Orcid: http://orcid.org/0000-0002-7040-8146

E-mail:sandra.motta@ucp.br

Natany Martins Bersan: Mestranda em Educação pela Universidade Católica de Petrópolis, graduada em Letras-Inglês pela Universidade Federal de Juiz de Fora e graduada em Jornalismo pelo Centro de Ensino Superior de Juiz de Fora. Possui MBA em Gestão de Escola Particular e competências de Liderança.

Orcid: https://orcid.org/0000-0002-2509-3691

E-mail: natanybersan@hotmail.com

Este periódico utiliza a licença Creative Commons Attribution 3.0, para periódicos de acesso aberto (Open Archives Iniciative - OAI). 